\title{
EN-BLOC PANCREATODUODENECTOMY AND RIGHT HEMICOLECTOMY FOR TREATING LOCALLY ADVANCED RIGHT COLON CANCER (T4): a series of five patients
}

\author{
Sergio Renato Pais COSTA ${ }^{1}$, Alexandre Cruz HENRIQUES ${ }^{1}$, Sergio Henrique Couto HORTA ${ }^{1}$, \\ Jaques WAISBERG² and Manlio Basílio SPERANZINI ${ }^{2}$
}

\begin{abstract}
A series of five cases of right-colon adenocarcinoma that invaded the proximal duodenum is presented. All patients underwent successful en-bloc pancreatoduodenectomy plus right hemicolectomy by General Surgery Service of the Teaching Hospital of the ABC Medical School, Santo André, SP, Brazil. The study was conducted between 2000 and 2007. There were two major complications but no mortality. Three patients did not present any recurrence over the course of 15 to 54 months of follow-up. Multivisceral resection with en-bloc pancreatoduodenectomy should be considered for patients who are fit for major surgery but do not present distant dissemination. Long-term survival may be attained.
\end{abstract}

HEADINGS - Pancreatoduodenectomy. Colonic neoplasms. Adenocarcinoma. Treatment outcome.

\section{INTRODUCTION}

In cases of colon cancer that adheres to adjacent structures, there is a local treatment failure rate of $36 \%$ to $53 \%$ following complete resection. This is more commonly seen in the cases in which neighboring organs or structures are involved. Extended or multivisceral resection is the treatment of choice. Locally advanced cancer of the right colon that adheres to the proximal duodenum or head of the pancreas presents a challenging problem, even for skilled surgeons. This situation may require complex and difficult surgical resolution ${ }^{(1,2,3,4,5)}$.

The present study reports on five cases of en-bloc pancreatoduodenectomy plus right hemicolectomy for locally advanced right colon cancer (T4).

\section{METHODS}

Between January 2000 and June 2007, five patients with locally advanced right colon cancer were operated by General Surgery Service, at the Teaching Hospital, "Faculdade de Medicina do ABC", Santo André, SP, Brazil. It was included in this study: four men and one women, age range of 38 to 53 years. Four patients were white and one black. All patients were followed-up by the General Surgery Service, at the mentioned Teaching Hospital. All patients had their disease documented by clinical and radiological methods, confirmed by pathological analysis (adenocarcinoma). All patients underwent surgical treatment for their colonic neoplasm. The hospital Ethics Committee approved this study. Symptoms and clinical signs presented were abdominal pain $(n=5)$, weight loss $(n=5)$, diarrhea $(n=3)$, gastrointestinal bleeding $(n=2)$, abdominal mass $(n=1)$, constipation $(n=1)$.

All patients realized upper gastrointestinal endoscopy, upper gastrointestinal examination and abdominal computed tomography.

\section{RESULTS}

All patients were submitted to surgical resection of their tumors (R0 - curative intent). There was no postoperative mortality. Three postoperative complications were observed. Two patients underwent major complications and were submitted surgical intervention. Immunohistochemical staining confirmed the colonic origin in all cases. All resections except one presented free margins. Two patients presented hepatic recurrence (13 and 24 months). Both them underwent exploratory laparotomy. Both cases were unresectable and they finally died. The follow-up period varied between 15 and 54 months. The surgical findings, histological characteristics and follow-up are shown in Table 1.

Institution: Serviço de Cirurgia Geral, Hospital Escola e Disciplina de Cirurgia do Sistema Digestivo, Faculdade de Medicina do ABC, Santo André, SP, Brasil

Serviço de Cirurgia Geral, Hospital Escola da Faculdade de Medicina do ABC. ${ }^{2}$ Disciplina de Cirurgia do Sistema Digestivo, Faculdade de Medicina do ABC, Santo André, SP, Brasil

Correspondence: Dr. Sergio Renato Pais Costa - Instituto de Oncologia São Paulo - Avenida Pacaembu, 1400 - 01234-200 - São Paulo, SP, Brazil. E-mail: sergiorenatopais@ ig.com.br 
TABLE 1. Surgical findings, histological characteristics and follow-up

\begin{tabular}{|c|c|c|c|c|c|}
\hline Case & 1 & 2 & 3 & 4 & 5 \\
\hline Surgical procedure & En-bloc GDP + RH & En-bloc PPPD + RH + RN & En-bloc GDP + RH & En-bloc GDP + RH & $\begin{array}{c}\text { En-bloc PPPD + RH + IVB-V } \\
\text { hepatic bisegmentectomy }\end{array}$ \\
\hline Operative time (minutes) & 340 & 400 & 380 & 360 & 435 \\
\hline Transfusions (mL) & - & 1500 & 1200 & 900 & 2100 \\
\hline Hospitalar stay (days) & 10 & 8 & 12 & 29 & 21 \\
\hline Postoperative complications & evisceration & - & - & abdominal abscess & pancreatic leakage \\
\hline Operative radicality & R0 & R0 & R1 & R0 & R0 \\
\hline TNM classification & T4N0 & T4N0 & T4N1 & T4N0 & T4N0 \\
\hline Grade tumor & II & II & III & I & II \\
\hline Recurrence time (m) & - & 24 & 13 & - & - \\
\hline Status & Alive & Died & Died & Alive & Alive \\
\hline Follow-up (m) & 54 & 30 & 15 & 15 & 20 \\
\hline
\end{tabular}

GDP = gastroduodenopancreatectomy

\section{DISCUSSION}

Five per cent to $12 \%$ of colon cancers present contiguous involvement of adjacent structures ${ }^{(4)}$. Specifically for right colon cancer or proximal transverse colon cancer, between $11 \%$ and $28 \%$ of the cases present adjacent organ invasion. Generally, the organs most invaded are the duodenum or the head of the pancreas ${ }^{(2)}$.

Patient who present locally advanced right colon cancer may have a variety of clinic conditions. The main findings that have been described are: gastrointestinal bleeding, anorexia, weight loss and diarrhea. Sometimes, diarrhea may indicate a duodenocolic fistula.

Computed tomography may sometimes show a hypodense mass in which the adjacent organs are involved, as in the fifth case of this study. More rarely, preoperative radiological examination may show no locoregional invasion until invasion of neighboring organs is diagnosed at the intraoperative evaluation, as we observed in case 2 of the present study. It may sometimes be impossible to determine whether the adherences are malignant or benign ${ }^{(3)}$.

Multivisceral resection must be restricted to patients in a good clinical condition who do not present any distant spreading. Following R0 multivisceral resection, the mean length of survival has been found to be around 40 months, while the overall 5 -year survival rate is close to $50 \%{ }^{(3)}$. Specifically in cases of $\mathrm{T} 4$ right colon cancer that undergo extended resection with pancreatoduodenectomy, the median disease-free period may reach 54 months ${ }^{(4)}$.

On the other hand, when patients undergo palliative bypass, the mean length of survival is 9 months and, in cases of incomplete resection (R1-2), the mean length of survival is 11 months $^{(4)}$. This hypothesis is favored by the fact that there is a specific subgroup of locally aggressive tumors. Like CURLEY et al.(2), in the present study it was observed that locally aggressive behavior could nevertheless be observed in T4 right colon cancers. In this series, the incidence of compromised lymph nodes was low (20\%), which therefore shows that the spreading was solitary and local.

Reviewing the literature showed that multivisceral resection should be the therapeutic choice in cases of locally advanced colon cancer without distant metastasis, provided that the patient presents good clinical performance. Even en-bloc pancreatoduodenectomy should sometimes be performed with the aim of achieving free margins ${ }^{(1,2,3,4,5)}$.

\section{CONCLUSION}

In summary, en-bloc multivisceral resection such as pancreatoduodenectomy plus right hemicolectomy for cases of locally advanced right colon cancer may offer long-term survival in selected cases. This approach also achieves good quality of life for patients with T4 right colon cancer. 
Costa SRP, Henriques AC, Horta SHC, Waisberg J, Speranzini MB. Duodenopancreatectomia e hemicolectomia em monobloco para o tratamento do câncer de cólon direito localmente avançado (T4): uma série de cinco doentes. Arq Gastroenterol. 2009;46(2):151-3.

RESUMO - Série de cinco casos de adenocarcinoma de cólon direito com invasão do duodeno proximal é apresentada. Todos os doentes realizaram uma duodenopancreatectomia com hemicolectomia direita em monobloco pelo Serviço de Cirurgia Geral do Hospital de Ensino da Faculdade de Medicina do ABC, Santo André, SP. O período de estudo foi entre 2000 e 2007. Houve duas complicações maiores, contudo a mortalidade foi nula. Três doentes não apresentaram recurrência entre 15 e 54 meses de seguimento. Ressecção multivisceral com pancreaticoduodenectomia e hemicolectomia direita em monobloco deve ser considerada para doentes hígidos sem disseminação à distância. Sobrevida em longo prazo pode ser atingida.

DESCRITORES - Pancreaticoduodenectomia. Neoplasias do colo. Adenocarcinoma. Resultado de tratamento.

\section{REFERENCES}

1. Berrospi F, Celis J, Ruiz E. En-bloc pancreaticoduodenectomy for right colon cancer invading adjacent organs. J Surg Oncol. 2002;79:174-99.

2. Curley SA, Evans DB, Ames FC. Resection for cure carcinoma of the colon directly invading the duodenum or pancreatic head. J Am Coll Surg. 1994;179:587-92.

3. Kaapor S, Das B, Pal S, Sanhi P, Chattopadhyay TK. En bloc resection of rightsided colonic adenocarcinoma with adjacent organ invasion. Int $\mathrm{J}$ Colorectal Dis. 2006;21:265-8
4. Koea JB, Conlon K, Paty PB, Guillem JG, Cohen AM. Pancreatic or duodenal resection or both for advanced carcinoma on the right colon: is it justified? Dis Colon Rectum. 2000;43:460-5.

5. Yoshimi F, Asato Y, Kuroki Y, Shioyama Y, Hori M, Itabashi M, Amemiya R, Koizumi S. Pancreaduodenectomy for locally advanced or recurrent colon cancer: report of two cases. Surg Today. 1999;29:906-10.

Recebido em 5/6/2008 Aprovado em 22/9/2008 